\title{
Peningkatan Efisiensi Waktu dan Biaya Pemeliharaan Overhaul Pesawat Tempur
}

\author{
Ellysa Nursanti $^{1 *}$ R. M. Suaidy Avief ${ }^{2}$, Sibut $^{3}$, Mariza Kertaningtyas ${ }^{4}$ \\ 1 Program Studi Teknik Industri, Program Pascasarjana, Institut Teknologi Nasional Malang \\ 2 Satuan Pemeliharaan 32 Depo Pemeliharaan 30, Lanud Abdulrachman Saleh Malang \\ 3,4 Program Studi Teknik Mesin, Fakultas Teknologi Industri , Institut Teknologi Nasional Malang \\ * E-mail: ellysa.nursanti@lecturer.itn.ac.id
}

\begin{abstract}
Abstrak
Pertahanan udara di suatu negara mutlak memerlukan ketersediaan seluruh sarana prasarana pendukung yang memadai, diantaranya adalah ketersediaan pesawat tempur. Lamanya periode waktu yang diperlukan untuk melakukan pemeliharaan overhaul pesawat tempur memberikan dampak signifikan terhadap ketersediaannya dalam mendukung system pertahanan Negara. Salah satu pesawat tempur tersebut adalah pesawat tempur Hawk Mk-209 yang berdasarkantechnical order/maintenance manual membutuhkan waktu overhaul 101.848 menit atau setara 14 bulan.Pendekatan model matematik optimasi dikembangkan untuk mendapatkan solusi optimum, dalam hal ini adalah untuk meminimumkan waktu overhaul pemeliharaan untuk pesawat tempur Hawk Mk-209. Metode Jalur Lintasan Kritis (Critical Path Method/CPM) dan Program Evaluation and Review Technique/PERT digunakan untuk mendukung tercapainya solusi optimal.Melalui optimasi dan CPM PERT diperoleh waktu pemeliharaan overhaul 28.984,50 detik atau setara 4,61 bulan. Dengan demikian diperoleh peningkatan efisiensi waktu dan biaya sebesar $67 \%$.
\end{abstract}

Kata Kunci : Efisiensi, Pemeliharaan, Optimasi, CPM, PERT, Pesawat Tempur

\section{Pendahuluan}

Pemeliharaan pesawat adalah kombinasi dari tugas-tugas rumit yang menjamin keamanan teknisi, kelaikan pesawat terbang serta keselamatan penumpang dimana beban kerja dibagi menjadi garis dasar pemeliharaan [1]. Maka, dalam melakukan pemeliharaan, sangat perlu untuk memperhitungkan produktivitas pemeliharaan yang dimiliki suatu Depo Pemeliharaan (Depohar) [2]. Kondisi saat ini pada pemeliharaan tingkat berat/overhaul pesawat Hawk Mk-209 total waktu pelaksanaannya berdasarkantechnical order/maintenance manual adalah 101.848 menit atau 1.697,46 jam atau 283 hari atau 14 bulan dengan asumsi waktu normal adalah 1 hari (6 jam), 1 minggu (5 hari kerja), 1 bulan (4 minggu), dan 1 tahun (12 bulan) [3]. Kondisi inidapat mengurangi ketersediaan kesiapan pesawat di Skadron Udara, untuk patroli rutin.Ketersediaan pesawatyang rendah juga berpeluang mengurangiskill penerbang Hawk Mk-209 menjadi kurang terlatih sehingga berpotensi menyebabkanincident dan accident yang tidak diinginkan.

Beberapa penelitian mengenai perencanaan penjadwalan pemeliharaan pesawat terbang telah dilakukan oleh [4], [5], [6], [7] dan [8] dengan menggunakan beberapa pendekatan yaitu CPM, MRP and PAC. Penelitian-penelitian tersebut menggunakan obyek pesawat terbang komersial. Sementara itu, pada pemeliharaan overhaul pesawat tempur, memiliki sedikit karakteristik yang berbeda, dimana pada pesawat tempur, waktu pemeliharaan harus dibuat seketat mungkin sehingga dapat mendukung penuh kebutuhan pertahanan keamanan Negara. Kondisi ini melatarbelakangi perlunya dilakukan penelitian untuk meminimumkan waktu pemeliharaan overhaul pesawat tempur, dalam hal ini Hawk Mk-209 sehingga dapat diperoleh peningkatan efisiensinya baik dari segi waktu maupun biaya. 


\section{Metodologi}

Metode yang digunakan pada penelitian ini adalah optimasi melalui pemodelan matematik dengan dukungan CPM dan PERT melalui perangkat lunak program komputer POM. Langkahlangkah detail dapat dilihat pada Gambar 1 berikut.

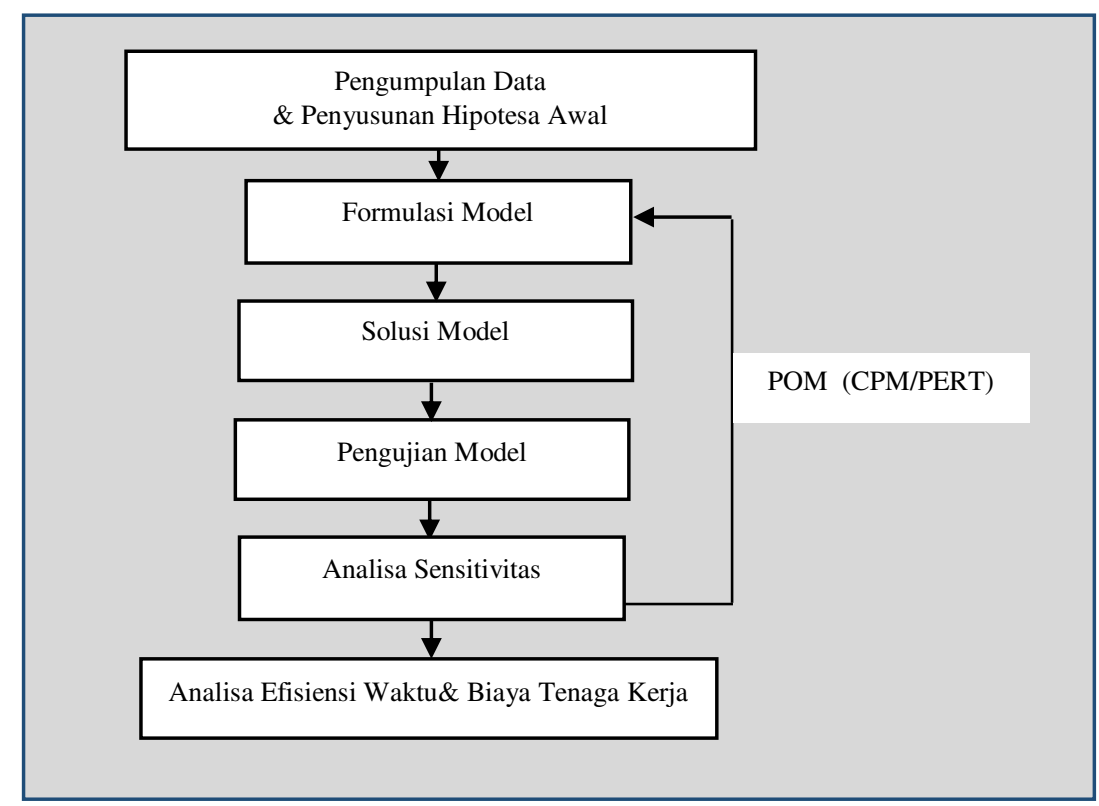

Gambar 1. Metode Penelitian

\section{Mathematical Modelling}

Berikut adalah diagram sistem input output yang mendasari formulasi model optimasi (Gambar 2).

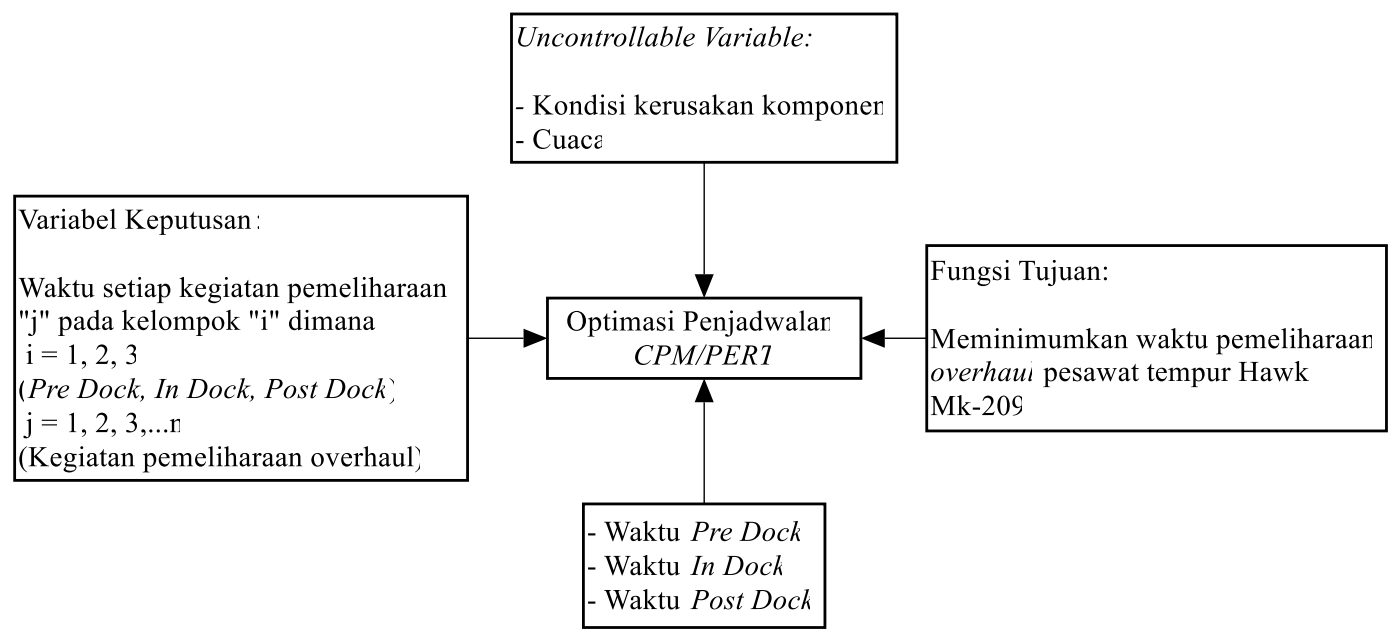

Gambar 2.Diagram Sistem Input Output 
a. Variabel keputusan.

$$
\begin{aligned}
& X_{i j} \text { dimana } i=1,2,3 \text { (mewakili Pre Dock, In Dock, Post Dock) } \\
& \qquad \mathrm{j}=1,2,3, \ldots \mathrm{n} \text { (mewakili setiap kegiatan pemeliharaan) }
\end{aligned}
$$

b. Fungsi Tujuan

Meminimumkan waktu pemeliharaan overhaul pesawat tempur Hawk Mk-209

Waktu overhaul= waktu pre dock + waktu in dock + waktu post dock

$$
\underset{\text { Pre Dock }}{\left(\sum_{j=1}^{n} \mathrm{X}_{1 \mathrm{j}}, \forall \mathrm{j}=1,2, \ldots \mathrm{n}\right)}+\underset{\substack{\text { Mn Dock } \\ \text { Post Dock }}}{\left(\sum_{j=1}^{n} \mathrm{X}_{2 \mathrm{j}}, \forall \mathrm{j}=1,2, \ldots \mathrm{n}\right)}+\left(\sum_{j=1}^{n} \mathrm{X}_{3 \mathrm{j}}, \forall \mathrm{j}=1,2, \ldots \mathrm{n}\right)
$$$$
\sum_{i=1}^{3} \sum_{j=1}^{n} x_{i j}, \forall i=1,2,3 ; j=1,2, \ldots n
$$

c. Fungsi Kendala (Tabel 1)

1. Non negatif: $X_{i j} \geq 0 ; i=1,2,3 ; j=1,2, \ldots n$

\begin{tabular}{|c|c|c|c|c|}
\hline & & & & \\
\hline$X_{11} \geq 165$ & $X_{211} \geq 60$ & $X_{224} \geq 120$ & $X_{237} \geq 60$ & $X_{250} \geq 30$ \\
\hline$X_{12} \geq 660$ & $X_{212} \geq 90$ & $X_{225} \geq 60$ & $X_{238} \geq 120$ & $X_{251} \geq 60$ \\
\hline & $X_{213} \geq 240$ & $X_{226} \geq 60$ & $X_{239} \geq 180$ & $X_{252} \geq 60$ \\
\hline$X_{21} \geq 165$ & $X_{214} \geq 990$ & $X_{227} \geq 240$ & $X_{240} \geq 120$ & $X_{253} \geq 90$ \\
\hline$X_{22} \geq 317$ & $X_{215} \geq 990$ & $X_{228} \geq 180$ & $\mathrm{X}_{241} \geq 90$ & $X_{254} \geq 60$ \\
\hline$X_{23} \geq 60$ & $X_{216} \geq 240$ & $X_{229} \geq 180$ & $X_{242} \geq 90$ & $X_{255} \geq 60$ \\
\hline$X_{24} \geq 120$ & $X_{217} \geq 495$ & $X_{230} \geq 990$ & $X_{243} \geq 120$ & $X_{256} \geq 60$ \\
\hline$X_{25} \geq 660$ & $X_{218} \geq 120$ & $X_{231} \geq 30$ & $X_{244} \geq 120$ & $X_{257} \geq 60$ \\
\hline$X_{26} \geq 120$ & $X_{219} \geq 180$ & $X_{232} \geq 60$ & $X_{245} \geq 180$ & $X_{258} \geq 240$ \\
\hline$X_{27} \geq 330$ & $X_{220} \geq 240$ & $X_{233} \geq 330$ & $X_{246} \geq 330$ & $X_{259} \geq 120$ \\
\hline$X_{28} \geq 120$ & $X_{221} \geq 240$ & $X_{234} \geq 60$ & $X_{247} \geq 330$ & $X_{260} \geq 60$ \\
\hline$X_{29} \geq 660$ & $X_{222} \geq 180$ & $X_{235} \geq 60$ & $\mathrm{X}_{248} \geq 330$ & $X_{261} \geq 60$ \\
\hline$X_{210} \geq 495$ & $X_{223} \geq 60$ & $X_{236} \geq 60$ & $X_{249} \geq 30$ & $X_{262} \geq 60$ \\
\hline$X_{263} \geq 60$ & $X_{294} \geq 120$ & $X_{2124} \geq 60$ & $X_{2154} \geq 60$ & $X_{2184} \geq 60$ \\
\hline$X_{264} \geq 60$ & $X_{295} \geq 60$ & $X_{2125} \geq 90$ & $X_{2155} \geq 60$ & $X_{2185} \geq 60$ \\
\hline$X_{265} \geq 60$ & $X_{296} \geq 60$ & $X_{2126} \geq 60$ & $X_{2156} \geq 120$ & $X_{2186} \geq 60$ \\
\hline$X_{267} \geq 120$ & $X_{297} \geq 60$ & $X_{2127} \geq 60$ & $X_{2157} \geq 120$ & $X_{2187} \geq 60$ \\
\hline$X_{268} \geq 120$ & $X_{298} \geq 60$ & $X_{2128} \geq 60$ & $X_{2158} \geq 60$ & $X_{2188} \geq 120$ \\
\hline$X_{269} \geq 120$ & $X_{299} \geq 60$ & $X_{2129} \geq 60$ & $X_{2159} \geq 60$ & $X_{2189} \geq 60$ \\
\hline$X_{270} \geq 180$ & $X_{2100} \geq 120$ & $X_{2130} \geq 60$ & $X_{2160} \geq 60$ & $X_{2190} \geq 60$ \\
\hline$X_{271} \geq 90$ & $X_{2101} \geq 60$ & $X_{2131} \geq 60$ & $X_{2161} \geq 30$ & $X_{2191} \geq 60$ \\
\hline$X_{272} \geq 60$ & $X_{2102} \geq 60$ & $X_{2132} \geq 60$ & $X_{2162} \geq 120$ & $X_{2192} \geq 60$ \\
\hline$X_{273} \geq 120$ & $X_{2103} \geq 120$ & $X_{2133} \geq 60$ & $X_{2163} \geq 60$ & $X_{2193} \geq 60$ \\
\hline$X_{274} \geq 120$ & $X_{2104} \geq 80$ & $X_{2134} \geq 60$ & $X_{2164} \geq 660$ & $X_{2194} \geq 120$ \\
\hline$X_{275} \geq 60$ & $X_{2105} \geq 240$ & $X_{2135} \geq 60$ & $X_{2165} \geq 120$ & $X_{2195} \geq 60$ \\
\hline$X_{276} \geq 120$ & $X_{2106} \geq 120$ & $X_{2136} \geq 60$ & $X_{2166} \geq 60$ & $X_{2196} \geq 60$ \\
\hline$X_{277} \geq 120$ & $X_{2107} \geq 240$ & $X_{2137} \geq 60$ & $X_{2167} \geq 60$ & $X_{2197} \geq 120$ \\
\hline$X_{278} \geq 180$ & $X_{2108} \geq 60$ & $X_{2138} \geq 660$ & $X_{2168} \geq 60$ & $X_{2198} \geq 60$ \\
\hline$X_{279} \geq 60$ & $X_{2109} \geq 90$ & $X_{2139} \geq 240$ & $X_{2169} \geq 60$ & $X_{2199} \geq 60$ \\
\hline
\end{tabular}

2. Batasan waktu setiap kegiatan

$$
\text { "j" untuk } \mathrm{j}=1,2, \ldots \mathrm{n} \text { (satuan menit) }
$$

Tabel 1.Batasan Waktu Setiap Kegiatan 


\begin{tabular}{|c|c|c|c|c|}
\hline$X_{280} \geq 60$ & $X_{2110} \geq 60$ & $X_{2140} \geq 60$ & $X_{2170} \geq 60$ & $X_{2200} \geq 60$ \\
\hline$X_{281} \geq 60$ & $X_{2111} \geq 60$ & $X_{2141} \geq 60$ & $X_{2171} \geq 60$ & $X_{2201} \geq 60$ \\
\hline$X_{282} \geq 60$ & $X_{2112} \geq 60$ & $X_{2142} \geq 60$ & $X_{2172} \geq 120$ & $X_{2202} \geq 60$ \\
\hline$X_{283} \geq 60$ & $X_{2113} \geq 60$ & $\mathrm{X}_{2143} \geq 60$ & $X_{2173} \geq 120$ & $X_{2203} \geq 60$ \\
\hline$X_{284} \geq 60$ & $X_{2114} \geq 60$ & $X_{2144} \geq 60$ & $X_{2174} \geq 60$ & $X_{2204} \geq 180$ \\
\hline$X_{285} \geq 120$ & $X_{2115} \geq 60$ & $X_{2145} \geq 90$ & $X_{2175} \geq 60$ & $X_{2205} \geq 60$ \\
\hline$X_{286} \geq 120$ & $X_{2116} \geq 60$ & $X_{2146} \geq 60$ & $X_{2176} \geq 60$ & $X_{2206} \geq 60$ \\
\hline $\mathrm{X}_{287} \geq 90$ & $X_{2117} \geq 60$ & $X_{2147} \geq 120$ & $X_{2177} \geq 60$ & $X_{2207} \geq 60$ \\
\hline$X_{288} \geq 90$ & $X_{2118} \geq 60$ & $X_{2148} \geq 120$ & $X_{2178} \geq 120$ & $X_{2208} \geq 120$ \\
\hline$X_{289} \geq 120$ & $X_{2119} \geq 60$ & $X_{2149} \geq 60$ & $X_{2179} \geq 60$ & $X_{2209} \geq 60$ \\
\hline$X_{290} \geq 120$ & $X_{2120} \geq 120$ & $X_{2150} \geq 60$ & $X_{2180} \geq 60$ & $X_{2210} \geq 60$ \\
\hline$X_{291} \geq 60$ & $X_{2121} \geq 60$ & $X_{2151} \geq 1320$ & $X_{2181} \geq 60$ & $X_{2211} \geq 120$ \\
\hline$X_{292} \geq 60$ & $X_{2122} \geq 120$ & $X_{2152} \geq 60$ & $X_{2182} \geq 60$ & $X_{2212} \geq 180$ \\
\hline$X_{293} \geq 60$ & $X_{2123} \geq 60$ & $X_{2153} \geq 60$ & $X_{2183} \geq 60$ & $X_{2213} \geq 60$ \\
\hline$X_{2214} \geq 60$ & $X_{2244} \geq 60$ & $X_{2274} \geq 60$ & $X_{2304} \geq 60$ & $X_{2334} \geq 90$ \\
\hline$X_{2215} \geq 60$ & $X_{2245} \geq 120$ & $X_{2275} \geq 180$ & $X_{2305} \geq 90$ & $X_{2335} \geq 990$ \\
\hline$X_{2216} \geq 60$ & $X_{2246} \geq 60$ & $X_{2276} \geq 60$ & $X_{2306} \geq 60$ & $X_{2336} \geq 660$ \\
\hline$X_{2217} \geq 60$ & $X_{2247} \geq 60$ & $X_{2277} \geq 60$ & $X_{2307} \geq 60$ & $X_{2337} \geq 120$ \\
\hline$X_{2218} \geq 60$ & $X_{2248} \geq 60$ & $X_{2278} \geq 180$ & $X_{2308} \geq 120$ & $X_{2338} \geq 660$ \\
\hline$X_{2219} \geq 60$ & $X_{2249} \geq 60$ & $X_{2279} \geq 90$ & $X_{2309} \geq 150$ & $X_{2339} \geq 90$ \\
\hline$X_{2220} \geq 60$ & $X_{2250} \geq 60$ & $X_{2280} \geq 120$ & $X_{2310} \geq 120$ & $X_{2340} \geq 660$ \\
\hline$X_{2221} \geq 60$ & $X_{2251} \geq 60$ & $X_{2281} \geq 60$ & $X_{2311} \geq 120$ & $X_{2341} \geq 165$ \\
\hline$X_{2222} \geq 120$ & $x_{2252} \geq 60$ & $X_{2282} \geq 60$ & $X_{2312} \geq 240$ & $X_{2342} \geq 240$ \\
\hline$X_{2223} \geq 120$ & $X_{2253} \geq 60$ & $X_{2283} \geq 60$ & $X_{2313} \geq 90$ & $X_{2343} \geq 120$ \\
\hline$X_{2224} \geq 60$ & $X_{2254} \geq 60$ & $X_{2284} \geq 180$ & $X_{2314} \geq 240$ & $X_{2344} \geq 60$ \\
\hline$X_{2225} \geq 60$ & $X_{2255} \geq 60$ & $X_{2285} \geq 120$ & $X_{2315} \geq 330$ & $X_{2345} \geq 60$ \\
\hline$X_{2226} \geq 120$ & $X_{2256} \geq 120$ & $X_{2286} \geq 60$ & $X_{2316} \geq 180$ & $X_{2346} \geq 1320$ \\
\hline$X_{2227} \geq 120$ & $X_{2257} \geq 60$ & $X_{2287} \geq 30$ & $X_{2317} \geq 180$ & $X_{2347} \geq 1320$ \\
\hline$X_{2228} \geq 60$ & $X_{2258} \geq 60$ & $X_{2288} \geq 60$ & $X_{2318} \geq 120$ & $X_{2348} \geq 120$ \\
\hline$X_{2229} \geq 180$ & $X_{2259} \geq 120$ & $X_{2289} \geq 120$ & $X_{2319} \geq 1980$ & $X_{2349} \geq 120$ \\
\hline$X_{2230} \geq 60$ & $X_{2260} \geq 60$ & $X_{2290} \geq 60$ & $\mathrm{X}_{2320} \geq 180$ & $X_{2350} \geq 240$ \\
\hline$X_{2231} \geq 120$ & $X_{2261} \geq 60$ & $X_{2291} \geq 60$ & $X_{2321} \geq 1320$ & $X_{2351} \geq 60$ \\
\hline$X_{2232} \geq 60$ & $X_{2262} \geq 120$ & $X_{2292} \geq 60$ & $X_{2322} \geq 1320$ & $X_{2352} \geq 60$ \\
\hline$X_{2233} \geq 60$ & $X_{2263} \geq 60$ & $X_{2293} \geq 60$ & $X_{2323} \geq 60$ & $X_{2353} \geq 60$ \\
\hline$X_{2234} \geq 120$ & $X_{2264} \geq 90$ & $X_{2294} \geq 60$ & $X_{2324} \geq 330$ & $X_{2354} \geq 90$ \\
\hline$X_{2235} \geq 30$ & $X_{2265} \geq 90$ & $X_{2295} \geq 60$ & $X_{2325} \geq 495$ & $X_{2355} \geq 60$ \\
\hline$X_{2236} \geq 30$ & $X_{2266} \geq 120$ & $X_{2296} \geq 60$ & $X_{2326} \geq 660$ & $X_{2356} \geq 60$ \\
\hline$X_{2237} \geq 60$ & $X_{2267} \geq 120$ & $X_{2297} \geq 30$ & $X_{2327} \geq 90$ & $X_{2357} \geq 180$ \\
\hline$X_{2238} \geq 30$ & $X_{2268} \geq 90$ & $X_{2298} \geq 30$ & $X_{2328} \geq 990$ & $X_{2358} \geq 180$ \\
\hline$X_{2239} \geq 30$ & $X_{2269} \geq 90$ & $X_{2299} \geq 30$ & $X_{2329} \geq 180$ & $X_{2359} \geq 240$ \\
\hline$X_{2240} \geq 60$ & $X_{2270} \geq 60$ & $X_{2300} \geq 30$ & $X_{2330} \geq 120$ & $X_{2360} \geq 1980$ \\
\hline$X_{2241} \geq 60$ & $X_{2271} \geq 60$ & $X_{2301} \geq 30$ & $X_{2331} \geq 120$ & $X_{2361} \geq 120$ \\
\hline$X_{2242} \geq 120$ & $X_{2272} \geq 90$ & $X_{2302} \geq 30$ & $X_{2332} \geq 990$ & $X_{2362} \geq 60$ \\
\hline$X_{2243} \geq 60$ & $X_{2273} \geq 60$ & $X_{2303} \geq 60$ & $X_{2333} \geq 90$ & $X_{2363} \geq 60$ \\
\hline
\end{tabular}




\begin{tabular}{|c|c|c|c|c|}
\hline$X_{2364} \geq 60$ & $X_{2377} \geq 240$ & $X_{2390} \geq 1980$ & $X_{2403} \geq 1980$ & $X_{2416} \geq 30$ \\
$X_{2365} \geq 30$ & $X_{2378} \geq 180$ & $X_{2391} \geq 1980$ & $X_{2404} \geq 180$ & $X_{2417} \geq 120$ \\
$X_{2366} \geq 30$ & $X_{2379} \geq 160$ & $X_{2392} \geq 1980$ & $X_{2405} \geq 330$ & $X_{2418} \geq 120$ \\
$X_{2367} \geq 10$ & $X_{2380} \geq 80$ & $X_{2393} \geq 1980$ & $X_{2406} \geq 120$ & $X_{2419} \geq 120$ \\
$X_{2368} \geq 10$ & $X_{2381} \geq 495$ & $X_{2394} \geq 1980$ & $X_{2407} \geq 120$ & $X_{2420} \geq 600$ \\
$X_{2369} \geq 120$ & $X_{2382} \geq 660$ & $X_{2395} \geq 1980$ & $X_{2408} \geq 240$ & \\
$X_{2370} \geq 180$ & $X_{2383} \geq 60$ & $X_{2396} \geq 1980$ & $X_{2409} \geq 330$ & $X_{31} \geq 1320$ \\
$X_{2371} \geq 1320$ & $X_{2384} \geq 60$ & $X_{2397} \geq 1980$ & $X_{2410} \geq 180$ & $X_{32} \geq 479$ \\
$X_{2372} \geq 660$ & $X_{2385} \geq 330$ & $X_{2398} \geq 1980$ & $X_{2411} \geq 120$ & $X_{33} \geq 317$ \\
$X_{2373} \geq 240$ & $X_{2386} \geq 330$ & $X_{2399} \geq 1980$ & $X_{2412} \geq 240$ & $X_{34} \geq 317$ \\
$X_{2374} \geq 330$ & $X_{2387} \geq 330$ & $X_{2400} \geq 1980$ & $X_{2413} \geq 180$ & $X_{35} \geq 158$ \\
$X_{2375} \geq 165$ & $X_{2388} \geq 1980$ & $X_{2401} \geq 1980$ & $X_{2414} \geq 330$ & $X_{36} \geq 954$ \\
$X_{2376} \geq 165$ & $X_{2389} \geq 1980$ & $X_{2402} \geq 1980$ & $X_{2415} \geq 330$ & $X_{37} \geq 317$ \\
\hline
\end{tabular}

$$
\sum_{i=1}^{3} \sum_{j=1}^{n} x_{i j} \leq 101.847,80 ; i=1,2,3 ; j=1,2, \ldots n
$$

\section{Hasil dan Pembahasan}

Berdasarkan hasil optimasi CPM/PERT dapat diketahui bahwa nilai selesai akhir (Latest FinishLF) diperoleh 4,61 bulan seperti terlihat pada Tabel 2 .

Tabel 2. Latest Finish

\begin{tabular}{|c|c|}
\hline Activity Name & Task in Minutes \\
\hline A. Pre Dock & 458,67 \\
\hline \multicolumn{2}{|l|}{ B. In Dock } \\
\hline 1) Pembongkaran & $2.443,17$ \\
\hline 2) Pembersihan & $1.350,00$ \\
\hline \multirow[t]{4}{*}{ 3) Pemeriksaan } & $1.833,33$ \\
\hline & $2.616,67$ \\
\hline & 816,67 \\
\hline & $1.300,00$ \\
\hline 4) Perbaikan & 416,67 \\
\hline 5) Pemasangan & $5.867,33$ \\
\hline 6) Penyetelan & $4.716,67$ \\
\hline 7) Pengetesan & $10.534,00$ \\
\hline 8) Penimbangan & 660,00 \\
\hline C. Post Dock & 214,50 \\
\hline Minutes & $33.227,68$ \\
\hline Hour & 553,79 \\
\hline Day & 92,30 \\
\hline Month & 4,61 \\
\hline
\end{tabular}

\section{Kesimpulan}

Optimasi dengan CPM PERT dapat meminimumkan waktu pemeliharaan overhaulpesawat Hawk Mk-209 dari 14 bulan menjadi 4,61 bulan. Penghematan ini menghasilkan efisiensi waktu dan biaya 
sebesar 67\%.Efisiensi ini diperoleh dengan dukungan ketersediaan semua komponen suku cadang pengganti sesuai jumlah dan spesifikasinya serta tenaga kerja sesuai jumlah dan kualifikasinya.

\section{Daftar Referensi}

[1] Al-Shayea, M.A, 2012, Maintenance Capacity Planning: Determination of Maintenance Workforce, Riyadh Engineering, No.4, pp. 37-43.

[2] Dijkstra, Kroon, Salomon, Van Nunen dan Van Wassenhove, 1994,Planning the Size and Organization of KLM's Aircraft Maintenance Personel. Interfaces 24, pp. 47-58

[3] Maintenance Manual Hawk Mk-209 PK 101B-44209-5A1, Master Maintenance Schedule.

[4] Premaratne Samaranayake, Senevi Kiridena, 2012, Aircraft maintenance planning and scheduling: an integrated framework, School of Management, University of Western Sydney, Perth, Australia, School of Mechanical, Materials and Mechatronic Engineering, University of Wollongong, Wollongong, Australia

[5] Ps Vincentia, L Lilik, Rs Leopoldus, (Prosiding) Analisis Jaringan Kerja Untuk Penjadwalan Kegiatan Dan Alokasi Pembiayaan Pada Proyek Pembangunan Komplek Gedung Serbaguna Menggunakan Critical Path Method, Fakultas Sains dan Matematika Universitas Kristen Satya Wacana, Salatiga

[6] Siswanto. 2007. Pengantar Manajemen. Jakarta: PT. Bumi Aksara

[7] Heizer dan Render. 2011. Operations Management 10th Edition. New Jersey: Pearson.

[8] Muhammad Rizki Ridho, Syahrizal, Evaluasi Penjadwalan Waktu Dan Biaya Proyek Dengan Metode PERT dan CPM, Departemen Teknik Sipil, Universitas Sumatera Utara 